\title{
APLIKASI ANDROID KAMUS BAHASA INDONESIA-SASAK
}

\author{
Lalu Erwin Haris H․, Ahmad S. Pardiansyah² \\ 1,2Program Studi Teknik Informatika, STMIK Lombok \\ Jln. Basuki Rahmat No.105 Praya Lombok Tengah 83511 \\ 1erwinlalu740@gmail.com, ${ }^{2}$ ahmad.pardiansyah84@gmail.com
}

\begin{abstract}
Sasak language is one of the local languages used to communicate by people of Lombok, West Nusa Tenggara. But along with the development of technology, especially in the field of smartphones, Sasak language has begun to fade, not the least of Lombok people who do not understand the language vocabulary Lombok Sasak especially the current generation. It is caused by environmental factors family, school and friends that use the Indonesian language in everyday conversation.

The solution to these problems is to design an application Indonesian-Sasak dictionary based on Android. The main purpose of a dictionary application Indonesian-Sasak is to help them in finding a translation in Indonesian or Sasak language effectively and efficiently with the media smartphone. There are several stages in the making of this application, which analyzes the data by the method of SWOT analysis, application design using SDLC, the process of working with UML, and the implementation of the program model that has been generated.

Indonesian-Sasak dictionary application android generated based APPS shaped installer that can be used on Android-based smartphones with minimal version 2.2 Up to 5.0. In testing using the Black-box testing and trials on smartphones, applications can run smoothly.
\end{abstract}

Keywords : Android, Dictionary Indonesian-Sasak

\begin{abstract}
Abstrak
Bahasa Sasak adalah salah satu bahasa daerah yang digunakan untuk berkomunikasi oleh masyarakat Lombok, Nusa Tenggara Barat. Namun seiring dengan berkembangnya teknologi khususnya di bidang smartphone, bahasa Sasak sudah mulai pudar, tak sedikit orang Lombok yang tidak mengerti bahasa kosa kata Lombok Sasak apalagi generasi sekarang. Hal ini disebabkan oleh faktor lingkungan keluarga, sekolah dan teman-teman yang menggunakan bahasa Indonesia dalam percakapan sehari-hari.

Solusi untuk masalah ini adalah merancang sebuah aplikasi kamus Indonesia-Sasak berbasis Android. Tujuan utama aplikasi kamus Bahasa Indonesia-Sasak adalah untuk membantu mereka dalam menemukan terjemahan bahasa Indonesia atau bahasa Sasak secara efektif dan efisien dengan media smartphone. Ada beberapa tahap dalam pembuatan aplikasi ini, yang menganalisis data dengan metode analisis SWOT, perancangan aplikasi menggunakan SDLC, proses kerja dengan UML, dan implementasi model program yang telah dihasilkan.

Aplikasi kamus berbahasa Indonesia-android berbasis android berbasis APPS berbentuk installer yang bisa digunakan pada smartphone berbasis Android dengan versi minimal 2.2 hingga 5.0. Dalam pengujian menggunakan pengujian kotak hitam dan uji coba pada smartphone, aplikasi bisa berjalan lancar.
\end{abstract}

Kata kunci : Android, Kamus Bahasa Sasak - Indonesia 


\section{Pendahuluan}

Bahasa sasak merupakan salah satu bahasa daerah yang digunakan untuk berkomunikasi oleh masyarakat Lombok, Nusa Tenggara Barat. Namun seiring dengan perkembangan zaman, bahasa sasak sudah mulai memudar, tidak sedikit dari masyarakat Lombok yang kurang memahami kosakata bahasa sasak terutama masyarakat Lombok generasi saat ini.

Kurangnya pemahaman terhadap kosakata bahasa sasak dipengaruhi oleh beberapa faktor. pertama adalah lingkungan, percakapan seharihari dengan keluarga dan teman-teman menggunakan bahasa indonesia yang berdampak pada kesulitan mengikuti pelajaran bahasa daerah di kelas. Kedua adalah perkembangan teknologi yang begitu pesat.

Pesatnya Perkembangan dibidang teknologi informasi sekarang ini khususnya smartphone yang memberikan kemudahan bagi setiap individu untuk melakukan kegiatan dengan cepat, praktis dan fleksibel. aplikasi yang berbasis sistem operasi android pada Smartphone juga ikut mengalami perkembangan, baik aplikasi dalam bentuk hiburan, permainan, media sosial, maupun aplikasi pembelajaran. Seperti halnya aplikasi kamus berbasis android yang sangat praktis dan mudah digunakan sehingga banyak diminati oleh semua orang baik di kalangan masyarakat biasa maupun pelajar.

\section{Tinjuan Pustaka}

Intan Nur Farida (2014) penelitiannya tentang perancangan Aplikasi Kamus IndonesiaJawa Berbasis Android. Penelitian yang dilakukan dilatarbelakangi oleh pesatnya perkembangan jaman dan teknologi sehingga dirancang aplikasi kamus yang menyajikan penerjemahan dari bahasa Indonsia ke tiga tingkatan bahasa Jawa yaitu Ngoko, Karma Madya dan Karma Inggil bagi generasi muda yang tidak bisa berbahasa Jawa. Metode yang digunakan dalam penelitian adalah Squential Search dan JSON (Java Script Object Notation).

Andi Purwanto (2013) penelitiannya tentang Pembuatan Aplikasi Kamus Bahasa Indonesia-Bahasa Jawa-Aksara Jawa Berbasis Android. Aplikasi tranlator Jawa berbasis android dibuat menggunakan analisis kebutuhan dan analisis kelayakan dengan menggunakan eclipse sebagai produksi sistem. Pembuatan aplikasi bertujuan untuk mempermudah mengartikan bahasa Indonesia ke bahasa Jawa maupun ke aksara Jawa. Aplikasi ini mampu memberikan metode baru yang menyenangkan dan menarik pengguna dalam mempelajari aksara Jawa dan karma alus.

Kartika Yudha Pratama (2013) penelitiannya tentang Pengembangan Kamus Bahasa Jawa-Bahasa Indonesia menggunakan Java 2 Micro Edition (J2ME). Penelitiannya bertujuan untuk mengembangkan aplikasi kamus bahasa Jawa menggunakan J2ME, menguji kinerja aplikasi, serta mengetahui tingkat kelayakan aplikasi. Pengembangan aplikasi menggunakan tahap analisis, desain aplikasi, pengembangan aplikasi, implementasi dengan uji coba dan penilaian produk. Ahli software menyatakan aplikasi kamus yang dikembangkan dinyatakan lolos dari tahap pengujian UTC For Java Application.

Muhammad Fadlullah (2012) penelitiannya tentang Rancang Bangun Aplikasi Kamus JermanIndonesia Berbasis Android. Penelitiannya merancang kamus digital Jerman-Indonesia sebagai alat bantu bagi mereka yang sedang atau ingin belajar bahasa internasional yaitu bahasa jerman dalam menemukan kosa kata bahasa jerman. Metode pengembangan perangkat lunak yang digunakan adalah metode prototype, menggunakan bahasa pemrograman Java dan SQLite sebagai databasenya. Aplikasi yang dihasilkan hanya kompatibel dengan ponsel yang berbasis android dengan versi 2.2 dan selebihnya, hanya dapat menghasilkan terjemahan dalam bentuk kata bukan kalimat.

Dimas Hamka (2012) penelitiannya tentang Aplikasi Kamus Inggris-Indonesia-Indonesia Inggris Pada Platform Android. Penelitiannya adalah merancang aplikasi kamus translate yang dapat berjalan di platform android yang menjadi kamus elektronik generasi baru sebagai media penerjemahan kata dari bahasa IndonesiaInggris dan sebaliknya yang dapat digunakan kapanpun dan diakses dimanapun oleh semua lapisan masyarakat. Metode yang digunakan dalam penelitian adalah desain pengembangan sistem yaitu metode prototyping, bahasa pemrogaman menggunakan Java dengan JDK-6 update 29, adobe flash sebagai editor, androidsdk, dan android AVD sebagai emulator.

\section{Metodologi Penelitian}

Metodologi penelitian adalah uraian langkah-langkah atau cara-cara yang dilakukan dalam melakukan suatu penelitian. Metode penelitian yang digunakan dalam penyusunan laporan adalah sebagai berikut :

1. Metode Pengumpulan Data

2. Metode Analisis 
3. Metode Perancangan

4. Metode Testing

4. Hasil dan Pembahasan 4.1 Use Case Diagram

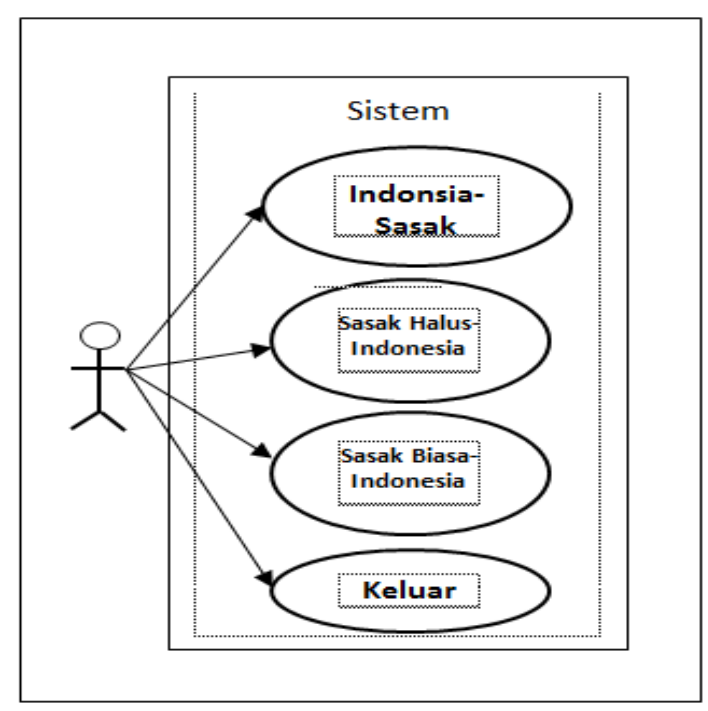

Gambar 1 Use Case Diagram

Use case diagram menggambarkan sistem yang diakses oleh satu aktor dan memiliki empat Use case.

Tabel 1 Keterangan Use Case Diagram

\begin{tabular}{|l|l|}
\hline \multicolumn{1}{|c|}{$\begin{array}{c}\text { Use case } \\
\text { Name }\end{array}$} & \multicolumn{1}{|c|}{ Use Case Description } \\
\hline $\begin{array}{l}\text { Indonesia- } \\
\text { Sasak }\end{array}$ & $\begin{array}{l}\text { Use case Indonesia-sasak } \\
\text { mendeskripsikan menu } \\
\text { tempat input kata, translate } \\
\text { dan pencarian hasil dari } \\
\text { terjemahan kata yang telah } \\
\text { diinputkan. }\end{array}$ \\
\hline $\begin{array}{l}\text { Sasak Halus } \\
\text { - Indonesia }\end{array}$ & $\begin{array}{l}\text { Use case Sasak Halus- } \\
\text { indonesia mendeskripsikan } \\
\text { menu tempat menginputkan } \\
\text { kata bahasa sasak dengan } \\
\text { halus ke bahasa Indonesia. }\end{array}$ \\
\hline $\begin{array}{l}\text { Sasak } \\
\text { Biasa- } \\
\text { Indonesia }\end{array}$ & $\begin{array}{l}\text { Use case Sasak biasa- } \\
\text { indonesia mendeskripsikan } \\
\text { menu tempat menginputkan } \\
\text { kata bahasa sasak dengan } \\
\text { bahasa sasak biasa ke bahasa } \\
\text { Indonesia. }\end{array}$ \\
\hline Keluar & $\begin{array}{l}\text { Use case mendeskripsikan } \\
\text { tombol untuk menu keluar. }\end{array}$ \\
\hline
\end{tabular}

Tabel 2 Spesifikasi Use Case translate

\begin{tabular}{|l|l|}
\hline \multicolumn{1}{|c|}{ Actor } & \multicolumn{1}{c|}{ User } \\
\hline Use case & Indonesia-Sasak \\
\hline
\end{tabular}

\begin{tabular}{|l|l|}
\hline Description & $\begin{array}{l}\text { User mengakses menu } \\
\text { translate Indonesia-sasak } \\
\text { untuk melakukan input kata } \\
\text { dan dan sistem memberikan } \\
\text { output terjemahan. }\end{array}$ \\
\hline $\begin{array}{l}\text { Pre } \\
\text { Condition }\end{array}$ & $\begin{array}{l}\text { Sistem menampilkan halaman } \\
\text { menu awal }\end{array}$ \\
\hline $\begin{array}{l}\text { Post } \\
\text { Condition }\end{array}$ & $\begin{array}{l}\text { Aktor berhasil melakukan } \\
\text { akses ke menu translate } \\
\text { Indonesia-sasak dan melihat } \\
\text { isi menu Indonesai-sasak. }\end{array}$ \\
\hline
\end{tabular}

Tabel 3 Spesifikasi Use Case Sasak HalusIndonesia

\begin{tabular}{|l|l|}
\hline \multicolumn{1}{|c|}{ Actor } & \multicolumn{1}{c|}{ User } \\
\hline Use case & Sasak Halus-Indonesia \\
\hline Description & $\begin{array}{l}\text { User mengakses menu Sasak } \\
\text { Halus-Indonesia untuk } \\
\text { melihat isi menu Sasak Halus- } \\
\text { Indonesia }\end{array}$ \\
\hline $\begin{array}{l}\text { Pre } \\
\text { Condition }\end{array}$ & $\begin{array}{l}\text { Sistem menampilkan halaman } \\
\text { menu awal }\end{array}$ \\
\hline $\begin{array}{l}\text { Post } \\
\text { Condition }\end{array}$ & $\begin{array}{l}\text { Aktor berhasil melakukan } \\
\text { akses ke menu translate } \\
\text { Sasak Halus-Indonesia dan } \\
\text { melihat isi menu Sasak halus- } \\
\text { Indonesia. }\end{array}$ \\
\hline
\end{tabular}

Tabel 4 Spesifikasi Use Case Sasak BiasaIndonesia

\begin{tabular}{|l|l|}
\hline \multicolumn{1}{|c|}{ Actor } & \multicolumn{1}{c|}{ User } \\
\hline Use case & Sasak biasa-Indonesia \\
\hline Description & $\begin{array}{l}\text { User mengakses menu Sasak } \\
\text { biasa-Indonesia untuk melihat } \\
\text { isi menu Sasak biasa- } \\
\text { Indonesia }\end{array}$ \\
\hline $\begin{array}{l}\text { Pre } \\
\text { Condition }\end{array}$ & $\begin{array}{l}\text { Sistem menampilkan halaman } \\
\text { menu awal }\end{array}$ \\
\hline Post & $\begin{array}{l}\text { Aktor berhasil melakukan } \\
\text { akses ke menu translate } \\
\text { Sandition biasa-Indonesia dan } \\
\text { melihat isi menu Sasak biasa- } \\
\text { Indonesia. }\end{array}$ \\
\hline
\end{tabular}

Tabel 5 Spesifikasi Use case Keluar

\begin{tabular}{|l|l|}
\hline \multicolumn{1}{|c|}{ Actor } & \multicolumn{1}{c|}{ User } \\
\hline Use case & Keluar \\
\hline Description & $\begin{array}{l}\text { User mengakses menu keluar } \\
\text { untuk keluar dari aplikasi }\end{array}$ \\
\hline $\begin{array}{l}\text { Pre } \\
\text { Condition }\end{array}$ & $\begin{array}{l}\text { Sistem menampilkan halaman } \\
\text { menu awal }\end{array}$ \\
\hline $\begin{array}{l}\text { Post } \\
\text { Condition }\end{array}$ & $\begin{array}{l}\text { Aktor berhasil melakukan } \\
\text { keluar dari aplikasi. }\end{array}$ \\
\hline
\end{tabular}




\subsection{Activity Diagram}

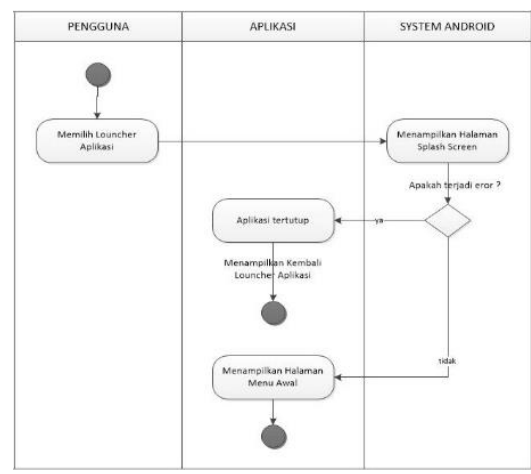

Gambar 2 Activity Diagram

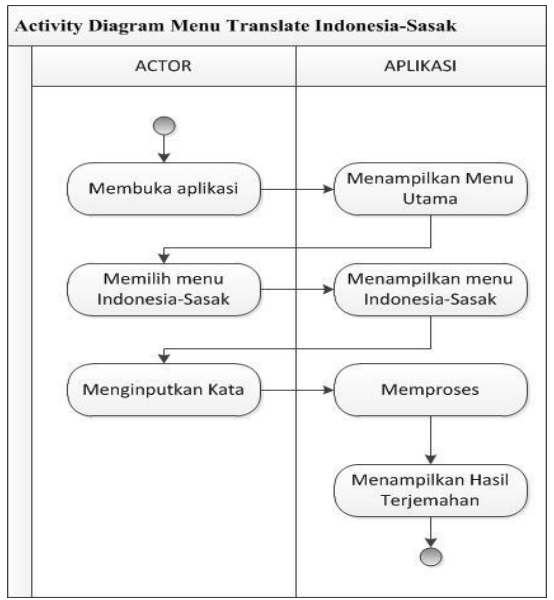

Gambar 3 Activity Diagram Menu Translate

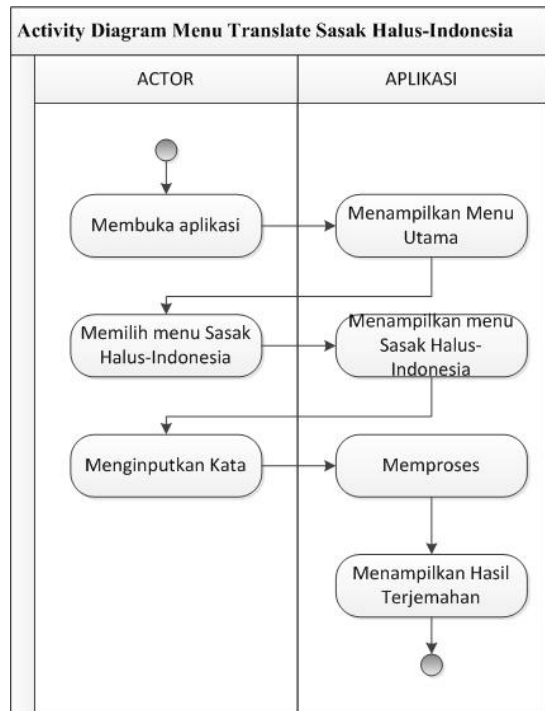

Gambar 4 Activity Diagram Menu SasakIndonesia

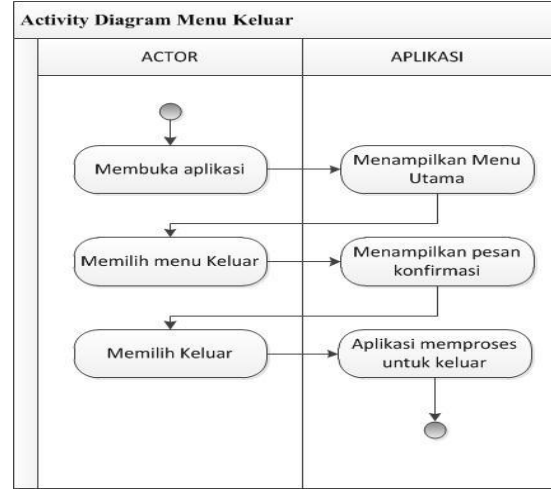

Gambar 5 Activity Diagram Menu Keluar

4.3 Sequence Diagram

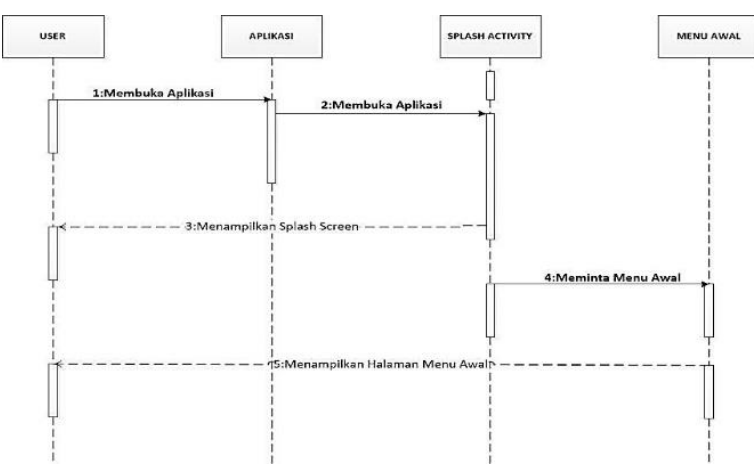

Gambar 6 Sequence Interface Menu Utama

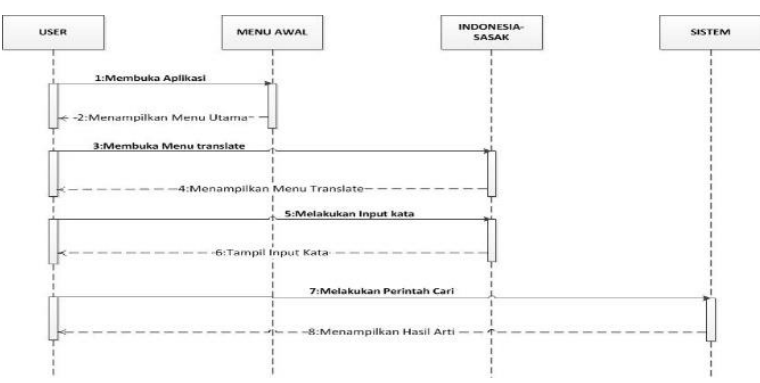

Gambar 7 Diagram translate

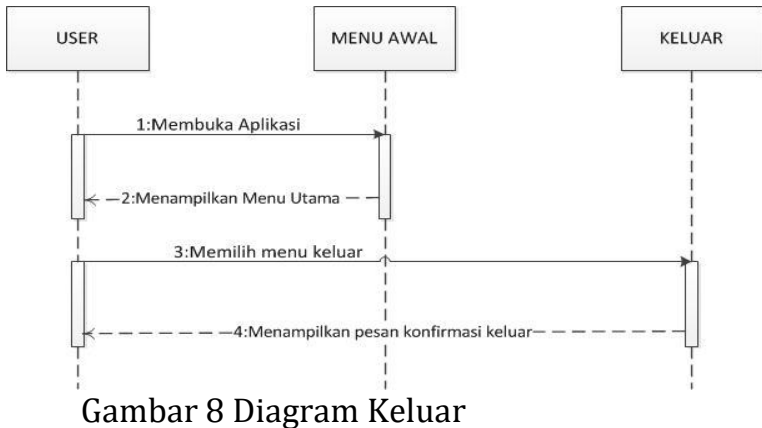

Dari Analisa Unified Modelling Language (UML) yang sudah dibahas penulis sebelumnya terdapat hasil perancangan aplikasi Android Kamus Bahasa Sasak seperti berikut: 


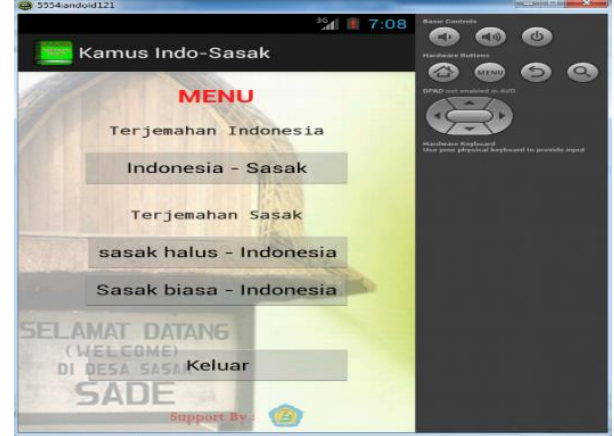

Gambar 9 Menu Utama

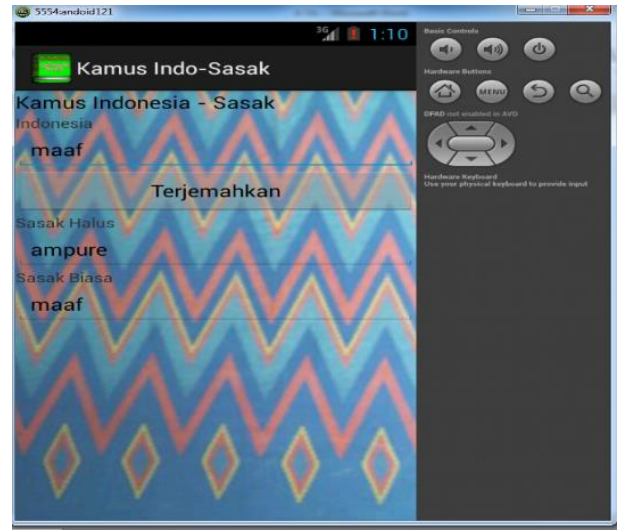

Gambar 10 Tampilan Menu Terjemahan

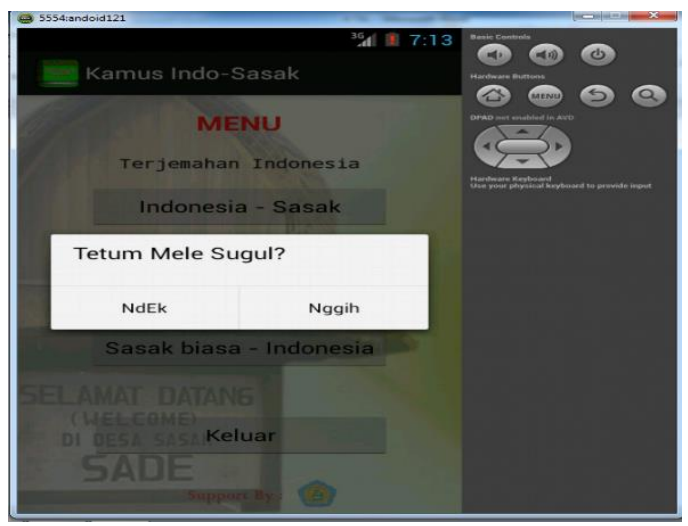

Gambar 11 Tampilan Menu Keluar

\section{Kesimpulan dan saran}

Kesimpulan dari penelitian ini adalah:

1. Aplikasi sudah dapat digunakan sebagai media pembelajaran bahasa sasak.

2. Aplikasi bersifat user friendly dan dapat dijalankan pada smartphone dengan sistem operasi android minimal versi Froyo 2.2 dan maksimal versi Jelly Bean 4.2

3. Dengan adanya aplikasi kamus bahasa Indonesia-Sasak berbasis android maka dapat mempermudah masyarakat lombok untuk lebih memperdalam bahasa sasak, selain itu dapat digunakan oleh semua kalangan pelajar serta para wisatawan dalam belajar bahasa sasak.
Saran dari penulis adalah dibutuhkan pengembangan Sistem Operasi Android versi terbaru yang memiliki keunggulan dan fasilitas yang lengkap, serta perlu adanya penambahan fitur suara dan fitur pembaharuan versi android terbaru.

\section{Daftar Pustaka:}

Arikunto, Suharsimi, 2005, Pendekatan dalam Proses Belajar Mengajar, Remaja Rosdakarya, Bandung.

Azhar, M., 1997, Kamus BAUSASTRA SasakIndonesia Indonesia-Sasak, Second Edition, PT. Intan Pariwara, Mataram.

Edward, Y., 2011, Exploring Android On Your PC, ANDI, Yogyakarta.

Rangkut, Freddy, 2006, Analisis SWOT Teknik Membedah Kasus Bisnis, PT. Gramedia Pustaka Utama, Jakarta.

S, Stephanus, H., 2011, Mudah Membuat Aplikasi Android, ANDI, Yogyakarta.

Wijono, M.S., 2004, Java 2 SE dengan Jbuilder, ANDI, Yogyakarta.

Pustaka Majalah, Jurnal IImiah atau Prosiding Farida, I. N., 2014, Aplikasi Kamus Bahasa Indonesia-Jawa Berbasis Android, Nusantara Of Engineering, ISSN: 2355-6684, Vol. 2, 2010

Lombok, Khairul Imtihan-STMIK. "Perencanaan Strategi Sistem Informasi Pendidikan Pada Sekolah Tinggi Manajemen Informatika dan Komputer (STMIK) Lombok." Bianglala Informatika 3.2 (2015).

Hodia, Maelani, and Khairul Imtihan-STMIK Lombok. "Perancangan Sistem Informasi Praktek Klinik Kebidanan (PKK) Pada Prodi DIII Kebidanan Stikes Qamarul Huda." IJNSIndonesian Journal on Networking and Security 6.3 (2017).

\section{Pustaka Laporan Penelitian}

Fadlullah, M., 2011, Rancang Bangun Aplikasi Kamus Jerman-Indonesia Berbasis Android, Skripsi, Fakultas Teknologi Informasi, UNISBANK, Semarang.

Pratama, K. Y., 2013, Pengembangan Kamus Bahasa Jawa-Bahasa Indonesia Menggunakan Java 2 Micro Edition (J2ME), Skripsi, Teknik Informatika, Universitas Negeri Yogyakarta, Yogyakarta.

Purwanto, A., 2013, Pembuatan Aplikasi Kamus Bahasa Indonesia-Bahasa Jawa-Aksara Jawa Berbasis Sistem Android, Skripsi, Sarjana Teknik Informatika, STMIK AMIKOM, Yogyakarta. 